\title{
Resequencing of the characterised CTGF gene to identify novel or known variants, and analysis of their association with diabetic nephropathy
}

Received: 12 October 2005/ Accepted: 20 December 2005/Published online: 24 February 2006

(C) The Japan Society of Human Genetics and Springer-Verlag 2006

\begin{abstract}
Connective tissue growth factor (CTGF) has been implicated in the pathogenesis of diabetic nephropathy; however, to date there have been no reports of genomic analysis on this gene. The $C T G F$ gene was comprehensively screened using WAVE (dHPLC) technology and direct capillary sequencing. Single nucleotide polymorphisms (SNPs) with minor allele frequencies greater than $5 \%$ were further investigated in an Irish, type 1 diabetic population. The case-control collection consisted of 272 diabetics with nephropathy and 367 non-nephropathic diabetic controls who were genotyped using TaqMan and Pyrosequencing technologies. Ten SNPs were identified, of which seven were novel. Four SNPs are located in the promoter, one in exon 2, two in intron 2 and three in the 3' untranslated region. Based on in silico analysis, three SNPs, c. $-650 \mathrm{G}>$ C, c. $-484 \mathrm{~T}>\mathrm{C}$ and c. $247 \mathrm{G}>\mathrm{C}$, are potentially functional. Subsequent statistical analysis for common SNPs, c. $-650 \mathrm{G}>\mathrm{C}$, c. $-420 \mathrm{InsT}$, c. $-220 \mathrm{G}>\mathrm{C}$, c. $289+94 \mathrm{~T}>\mathrm{C}$ and c. $289+98 \mathrm{~T}>\mathrm{C}$, in the case-control study revealed no significant differences in genotype or allele frequencies. CTGF has emerged as a biological candidate gene for diabetic nephropathy; however, no significant association was
\end{abstract}

Electronic Supplementary Material Supplementary material is available for this article at http://dx.doi.org/10.1007/s10038-0060368-7 and is accessible for authorized users.

A.J. McKnight $(\bowtie) \cdot D . A$. Savage · A.P. Maxwell

Nephrology Research Group, Queen's University of Belfast, c/o Regional Genetics Centre, Level A, Tower Block, Belfast City Hospital, Lisburn Road, BT9 7AB Belfast, Northern Ireland E-mail: a.j.mcknight@qub.ac.uk

Tel.: + 44-2890-329241

Fax: + 44-2890-236911

C.C. Patterson

Department of Epidemiology and Public Health,

Queen's University of Belfast, Belfast, Northern Ireland

H.R. Brady

Dublin Molecular Medicine Centre, Conway Institute, Dublin, Ireland detected between common $C T G F$ SNPs and nephropathy in this population.

Keywords Association - Connective tissue growth factor $\cdot$ Nephropathy $\cdot$ Gene $\cdot$ SNP Type 1 diabetes

\section{Introduction}

Connective tissue growth factor (CTGF) has recently been proposed to play a prominent role in the pathogenesis of diabetic nephropathy (van Nieuwenhoven et al. 2005). Diabetic nephropathy is the leading cause of end stage renal disease in the Western world (USRDS 2004), with substantial evidence for an inherited predisposition to diabetic nephropathy in a subset of type 1 diabetic patients (Quinn et al. 1996; Seaquist et al. 1989). To date, the major gene variants involved in predisposition to diabetic nephropathy have not been identified.

$C T G F$ is an excellent biological candidate gene for nephropathy given its role in extracellular matrix remodelling and its upregulation by the profibrotic transforming growth factor beta (TGF $\beta 1$ ) (van Nieuwenhoven et al. 2005). Increased CTGF levels have been detected in the glomeruli of patients with diabetic nephropathy (Adler et al. 2001) and urinary CTGF excretion correlates with the amount of albuminuria in type 1 diabetic patients (Gilbert et al. 2003). Increased in vivo CTGF mRNA and protein levels have been demonstrated in the glomeruli of diabetic animals with nephropathy (Murphy et al. 1999; Wahab et al. 2001), while in vitro studies have shown CTGF induction by high glucose (Murphy et al. 1999), advanced glycation end products (Twigg et al. 2001), reactive oxygen species (Park et al. 2001) and mechanical strain (Hishikawa et al. 2001).

The $C T G F$ gene maps to chromosomal location 6q23.1 (Martinerie et al. 1992); however, the genomic region has not yet been fully characterised. We screened the $C T G F$ gene to identify variants and employed a case- 
control study to assess association between selected polymorphisms and diabetic nephropathy in an Irish population.

\section{Subjects and methods}

Ethical approval was obtained from the appropriate Research Ethics Committees and written, informed consent obtained from individuals prior to conducting this study. All patients were at least third generation Irish Caucasians diagnosed with type 1 diabetes mellitus before 31 years of age, and required insulin from diagnosis. Patients with nephropathy (cases, $n=272$ ) had diabetes for at least 10 years before the onset of proteinuria $(>0.5 \mathrm{~g} / 24 \mathrm{~h})$, were on antihypertensive therapy, and demonstrated concurrent retinopathy. Patients without nephropathy (controls, $n=367$ ) had diabetes for at least 15 years with no evidence of microalbuminuria, were not in receipt of antihypertensive medication, and demonstrated no evidence of nondiabetic renal disease. There was no significant difference between cases and controls in mean age at onset [17.1 (SD 8.2) year vs 16.8 (SD 8.1) year], mean duration of diabetes ([26.9 (SD 8.3) year vs. 27.7 (SD 9.0) year] or mean $\mathrm{HbA} 1 \mathrm{c}$ value $[8.5$ (SD 1.7)\% vs. 8.4 (SD 1.6)\%]. As expected, average blood pressure was higher and more variable in the cases compared to the controls [systolic $=150.1(\mathrm{SD} 22.6) \mathrm{mm} \mathrm{Hg}$ vs 126.9 $(\mathrm{SD} 16.6) \mathrm{mm} \mathrm{Hg}$; diastolic $=86.5(\mathrm{SD} 11.4) \mathrm{mm} \mathrm{Hg}$ vs 76.1 (SD 7.3) $\mathrm{mm} \mathrm{Hg}$.

The nucleotide sequence of draft clone RP11-6918 for human chromosome 6 was downloaded from the National Centre for Biotechnology Information (http:// www.ncbi.nlm.nih.gov). Reference mRNA (NM_001901, gi:4503122) and protein (NP_001892.1, GI:4503123) sequences were used to determine exonintron boundaries. The promoter region was identified using ElDorado software from the Genomatix Suite, while MatInspector software (Cartharius et al. 2005) was used to assess the influence of identified single nucleotide polymorphisms (SNPs) in the promoter region on transcription factor binding sites. For screening purposes, 3,975 bases of genomic sequence for $C T G F$ were divided into 11 overlapping fragments (S1). The $C T G F$ gene, including the promoter, all exons, introns, $620 \mathrm{bp}$ upstream of the $5^{\prime}$ untranslated region and $216 \mathrm{bp}$ beyond the $3^{\prime}$ untranslated region were screened in 15 case and 15 control individuals. Each PCR product was then analysed on the WAVE (dHPLC) DNA Fragment Analysis System (Transgenomic, Crewe, UK) following the manufacturer's recommendations. Differentially separating fragments (representing DNA variants) were bidirectionally sequenced to identify variants using an ABI PRISM 3100 Genetic Analyser (Applied Biosystems, Warrington, UK). Forty-six healthy, Irish controls were genotyped by direct capillary sequencing (Applied Biosystems) to establish allele frequencies for all variants. Genotyping was performed on case and control DNAs for SNPs c. $-650 \mathrm{G}>\mathrm{C}$, c. $289+94 \mathrm{~T}>\mathrm{C}$ and c. $289+98 \mathrm{~T}>\mathrm{C}$ by Pyrosequencing (Biotage, Uppsala, Sweden), c. $-220 \mathrm{G}>\mathrm{A}$ employing TaqMan technology (Applied Biosystems) and c.-420InsT by direct capillary sequencing as this SNP was not amenable to the other technologies. Genotype frequencies were assessed for Hardy-Weinberg equilibrium using a $\chi^{2}$ goodness-of-fit test. The $\chi^{2}$ test for contingency tables was used to compare genotype and allele frequencies between case and control subjects with the level of significance set to $P<0.05$. Subgroup analyses on the basis of gender (female: cases, $n=112$; controls, $n=209$ ), duration of diabetes ( $<24$ years: cases, $n=101$; controls $n=143$ ) and retinopathy (with retinopathy, $n=399$; no evidence of retinopathy, $n=240$ ) was performed for all four SNPs. The extent of linkage disequilibrium (LD) was quantified using Lewontin's D' (Lewontin 1964). Haplotype frequencies were estimated and compared between cases and controls using the Chaplin program (Epstein and Satten 2003).

\section{Results and discussion}

Comparison of our resequenced genomic data with the protein and mRNA reference sequences revealed the $C T G F$ gene has five exons, where all exon-intron boundaries follow the consensus AG/GT rule (Mount 1982). The coding region of $C T G F$ spans 1,909 bases from the start (ATG) to the stop (TGA) codons; however, we comprehensively screened and resequenced almost $4 \mathrm{~kb}$ of this gene, including the promoter, all exons, introns and beyond the untranslated regions. There are presently no SNPs in dbSNP validated by frequency data, and no haplotype tagged SNPs recorded in the genomic region of $C T G F$ (gene id $=1490, \mathrm{NCBI}$, accessed 8 October 2005). As there was no genomic reference sequence available for the $C T G F$ gene in public repositories, we have submitted our annotated sequencing data as GenBank accession number DQ097843. Our resequenced data established six differences with the GenBank recorded draft sequence for this region of chromosome 6, RP11-6918 (c.247G, c.754-29delT) and the partial promoter sequence published for $C T G F, \mathrm{X} 92511$ c. $-401 \mathrm{C}>\mathrm{T}$, c. $-274 \mathrm{insG}$, c. $-250 \mathrm{ins} C$ and c. $-246 \mathrm{ins}$ ); this may be explained by the lower quality, draft raw sequence data generated by earlier, large-scale genotyping efforts. In total, we identified four SNPs in the promoter region, one in exon 2 , two in intron 2 and three in the $3^{\prime}$ untranslated region of the $C T G F$ gene. Two of these were previously recorded in dbSNP and we have obtained novel NCBI identifiers for the remaining eight SNPs (Table 1).

Using publicly available software, we identified two putatively functional SNPs in the promoter region of this gene, c. $-650 \mathrm{G}>\mathrm{C}$ and c. $-484 \mathrm{~T}>\mathrm{C}$, each of which are predicted to create a transcription factor binding site in the $C T G F$ gene. The c. $650 \mathrm{G}>\mathrm{C}$ SNP is located two bases from a putative myeloid zinc finger 1 binding site 
Table 1 Variant position, unique NCBI (http://www.ncbi.nlm.nih.gov) identifier and minor allele frequencies for identified variants in the connective tissue growth factor gene $(C T G F)$ in 46 healthy controls

\begin{tabular}{llll}
\hline Variant $^{\mathrm{a}}$ & $\begin{array}{l}\text { Unique NCBI } \\
\text { identifier }\end{array}$ & Location & $\begin{array}{c}\text { Minor allele } \\
\text { frequency (\%) }\end{array}$ \\
\hline c. $-650 \mathrm{G}>\mathrm{C}^{\mathrm{b}}$ & ss38347236 & Promoter & 6.5 \\
c. $-484 \mathrm{~T}>\mathrm{C}^{\mathrm{b}}$ & ss38347237 & Promoter & 2.2 \\
c. $-420 \mathrm{InsT} \mathrm{T}^{\mathrm{b}}$ & ss38347244 & Promoter & 6.5 \\
c. $-220 \mathrm{G}>\mathrm{A}^{\mathrm{b}}$ & ss38347238 & Promoter & 5.4 \\
c. $247 \mathrm{G}>\mathrm{C}$ & rs7451102 & Exon 2 & 1.1 \\
c. $289+94 \mathrm{~T}>\mathrm{C}^{\mathrm{b}}$ & ss38347240 & Intron 2 & 20.7 \\
c. $289+98 \mathrm{~T}>\mathrm{C}^{\mathrm{b}}$ & ss38347241 & Intron 2 & 20.7 \\
c. $622 \mathrm{~A}>\mathrm{G}$ & rs3210042 & 3' UTR & 3.3 \\
c. $* 816 \mathrm{C}>\mathrm{A}^{\mathrm{b}}$ & ss38347242 & 3' UTR & 1.1 \\
c. $* 1084 \mathrm{~A}>\mathrm{T}^{\mathrm{b}}$ & ss38347243 & 3' UTR & 1.1
\end{tabular}

${ }^{\mathrm{a}}$ Nomenclature for all variants follows the Human Genome Variation Society recommendations for coding sequences, updated 21 May 2005 (http://www.genomic.unimelb.edu.au/mdi/mutnomen) ${ }^{b}$ Novel NCBI identifiers were obtained for these single nucleotide polymorphisms (SNPs) as they were previously unrecorded in dbSNP

previously reported by a Danish group (Blom et al. 2001) with a similar minor allele frequency to that found in our study (Table 2). The exonic SNP c. $247 \mathrm{G}>\mathrm{C}$ (rs7451102) was detected in only one individual in our healthy control population, but was predicted to cause a non-synonymous amino acid change from a small aspartic acid to a larger histidine residue (p.Asp83His) in the insulin-like growth factor binding protein domain (Pfam: 00219), thus having a potentially functional effect on the CTGF protein.

Five SNPs demonstrated a minor allele frequency greater than $5 \%$ (Table 1) and were subsequently genotyped in an Irish, type 1 diabetic case-control cohort of 639 individuals ( 272 cases, 367 controls). The distribution of genotypes was found to be in HardyWeinberg equilibrium for all SNPs in both case and control groups. Significant association was not observed with either genotype $(P>0.9)$ or allele $(P>0.7)$ frequencies between case and control groups (Table 2). These sample sizes have $90 \%$ power to detect a doubling in the minor allele frequency in cases relative to controls (e.g. $10 \%$ vs $5 \%$ ). Further subgroup analyses for gender (genotype $P>0.4$ ), duration of diabetes (genotype $P>0.4$ ) and retinopathy (genotype $P>0.4$ ) also failed to reveal significant association. Highly statistically significant LD was observed for all five loci $(P<0.00001$, Table 3). Haplotype frequencies were estimated separately in case and control groups, with the same two haplotypes being found at frequencies greater than $5 \%$ in each group. From $5^{\prime}$ to $3^{\prime}$ c. $-650 \mathrm{G}>\mathrm{C}$, c. $-420 \mathrm{InsT}$, c. $-220 \mathrm{G}>\mathrm{C}$, c. $289+94 \mathrm{~T}>\mathrm{C}$, c. $289+98 \mathrm{~T}>\mathrm{C}), \mathrm{G}-\mathrm{GTT}$ was the most common haplotype (cases $=76.4 \%$, controls $=78.1 \%$ ), followed by G-GCC (cases $=13.4 \%$, controls $=10.9 \%$ ). A global test comparing these haplotype frequencies in cases and controls did not attain significance $\left(\chi^{2}=1.32, d f=2 ; P=0.57\right)$.

The relatively low number of SNPs identified in the $C T G F$ gene may reflect the diverse functions and high degree of conservation observed among different species (Moussad and Brigstock 2000). CTGF is involved in a multitude of physiological pathways and has been recently proposed as a potential therapeutic target for fibrotic diseases (Franklin 1997; van Nieuwenhoven et al. 2005; Twigg and Cooper 2004). Knowledge of the gene structure and variants should aid our understanding of $C T G F$ gene function and further the development of strategies to ameliorate the development and progression of diabetic nephropathy. We have submitted the annotated, 'corrected' genomic sequence for the $C T G F$ gene and have identified polymorphisms, seven of which are novel, which may influence the role of CTGF

Table 2 Genotype and allele frequencies for genotyped $C T G F$ SNPs in cases with diabetic nephropathy and controls without nephropathy. Data are $n(\%) . P$ values are presented from the $\chi^{2}$ analysis for both genotype and allele frequency comparisons between these groups

\begin{tabular}{|c|c|c|c|c|c|c|}
\hline SNP & $N$ & \multicolumn{2}{|l|}{ Genotypes } & \multicolumn{3}{|c|}{ Alleles } \\
\hline \multirow{3}{*}{ c. $-650 \mathrm{G}>\mathrm{C}$} & $\mathrm{GC}$ & $26(9.6 \%)$ & $38(10.4 \%)$ & & & \\
\hline & $\mathrm{CC}$ & $2(0.7 \%)$ & $2(0.5 \%)$ & $\mathrm{C}$ & $30(5.5 \%)$ & $42(5.7 \%)$ \\
\hline & $P$ & 0.91 & & & 0.87 & \\
\hline \multirow[t]{2}{*}{ c. $-420 \mathrm{InsT}$} & $-1-$ & $244(89.7 \%)$ & $329(89.6 \%)$ & - & $514(94.5 \%)$ & $694(94.6 \%)$ \\
\hline & $P$ & 0.95 & & & 0.96 & \\
\hline \multirow{4}{*}{ c. $-220 \mathrm{G}>\mathrm{A}$} & GG & $234(86.0 \%)$ & $312(85.0 \%)$ & G & $503(92.5 \%)$ & $675(92.0 \%)$ \\
\hline & GA & $35(12.9 \%)$ & $51(13.9 \%)$ & & & \\
\hline & AA & $3(1.1 \%)$ & $4(1.1 \%)$ & A & $41(7.5 \%)$ & $59(8.0 \%)$ \\
\hline & $P$ & 0.93 & & & 0.74 & \\
\hline c. $289+94 \mathrm{~T}>\mathrm{C}$, c. $289+98 \mathrm{~T}>\mathrm{C}$ & $\mathrm{TT}$ & $178(65.4 \%)$ & $238(64.9 \%)$ & $\mathrm{T}$ & $439(80.7 \%)$ & $590(80.4 \%)$ \\
\hline
\end{tabular}


Table 3 Linkage disequilibrium (LD) between common SNPs in the $C T G F$ gene. Data are $\left|\mathrm{D}^{\prime}\right|$, $p<0.00001$

\begin{tabular}{lllll}
\hline SNP & c. $-650 \mathrm{G}>\mathrm{C}$ & c. $-420 \mathrm{InsT}$ & c. $-220 \mathrm{G}>\mathrm{A}$ & c. $-289+94 \mathrm{~T}>\mathrm{C}$ \\
\hline c. -420 InsT & 0.63 & & & \\
c. $-220 \mathrm{G}>\mathrm{A}$ & 0.61 & 0.86 & & \\
c. $-289+94 \mathrm{~T}>\mathrm{C}$ & 0.71 & 0.78 & 0.69 & 1.00 \\
c. $-289+94 \mathrm{~T}>\mathrm{C}$ & 0.71 & 0.78 & 0.69 & 1.00 \\
\hline
\end{tabular}

in disease pathologies. To our knowledge, this is the first report describing variations in the complete $C T G F$ gene and assessing the influence of DNA variants on diabetic nephropathy. In our Irish type 1 diabetic population, our results suggest that common SNPs in CTGF do not play a major role in genetic susceptibility to diabetic nephropathy; however, this should be assessed in a larger study group.

Acknowledgements The Research and Development Office of Northern Ireland and the Health Research Board of Ireland funded this work. A.J.M. is supported by a Northern Ireland Kidney Research Fund postdoctoral fellowship.

\section{References}

Adler SG, Kang SW, Feld S, Cha DR, Barba L, Striker L, Striker G, Riser BL, LaPage J, Nast CC (2001) Glomerular mRNAs in human type 1 diabetes: biochemical evidence for microalbuminuria as a manifestation of diabetic nephropathy. Kidney Int 60:2330-2336

Blom IE, van Dijk AJ, de Weger RA, Tilanus MG, Goldschmeding $R$ (2001) Identification of human ccn2 (connective tissue growth factor) promoter polymorphisms. Mol Pathol 54:192-196

Cartharius K, Frech K, Grote K, Klocke B, Haltmeier M, Klingenhoff A, Frisch M, Bayerlein M, Werner T (2005) MatInspector and beyond: promoter analysis based on transcription factor binding sites. Bioinformatics 21:2933-2942

Epstein MP, Satten GA (2003) Inference on haplotype effects in case-controlstudies using unphased genotype data. Am J Hum Genet 73:1316-1329

Franklin TJ (1997) Therapeutic approaches to organ fibrosis. Int J Biochem Cell Biol 1:79-89

Gilbert RE, Akdeniz A, Weitz S, Usinger WR, Molineaux C, Jones SE, Langham RG, Jerums G (2003) Urinary connective tissue growth factor excretion in patients with type 1 diabetes and nephropathy. Diabetes Care 26(9):2632-2636

Hishikawa K, Oemar BS, Nakaki T (2001) Static pressure regulates connective tissue growth factor expression in human mesangial cells. J Biol Chem 276:16797-16803

Lewontin RC (1964) the interaction of selection and linkage. I: General considerations; heterotic models. Genetics 49:49-67
Martinerie C, Viegas-Pequignot E, Guenard I, Dutrillaux B, Nguyen VC, Bernheim A, Perbal B (1992) Physical mapping of human loci homologous to the chicken nov proto- oncogene. Oncogene 7:2529-2534

Mount SM (1982) A catalogue of splice junction sequences. Nucleic Acids Res 10:459-472

Moussad EE, Brigstock DR (2000) Connective tissue growth factor: what's in a name? Mol Genet Metab 71:276-92

Murphy M, Godson C, Cannon S, Kato S, Mackenzie HS, Martin F, Brady HR (1999) Suppression subtractive hybridization identifies high glucose levels as a stimulus for expression of connective tissue growth factor and other genes in human mesangial cells. J Biol Chem 274:5830-5834

Nieuwenhoven FA van, Jensen LJ, Flyvbjerg A, Goldschmeding R (2005) Imbalance of growth factor signalling in diabetic kidney disease: is connective tissue growth factor (CTGF, CCN2) the perfect intervention point? Nephrol Dial Transplant 20:6-10

Park SK, Kim J, Seomun Y, Choi J, Kim DH, Han IO, Lee EH, Chung SK, Joo CK (2001) Hydrogen peroxide is a novel inducer of connective tissue growth factor. Biochem Biophys Res Commun 284:966-971

Quinn M, Angelico MC, Warram JH, Krolewski AS (1996) Familial factors determine the development of diabetic nephropathy in patients with IDDM. Diabetologia 39:940-945

Seaquist ER, Goetz FC, Rich S, Barbosa J (1989) Familial clustering of diabetic kidney disease. Evidence for genetic susceptibility to diabetic nephropathy. N Engl J Med 320:1161-1165

Twigg SM, Cooper ME (2004) The time has come to target connective tissue growth factor in diabetic complications. Diabetologia 47:965-968

Twigg SM, Chen MM, Joly AH, Chakrapani SD, Tsubaki J, Kim HS, Oh Y, Rosenfeld RG (2001) Advanced glycosylation end products up-regulate connective tissue growth factor (insulinlike growth factor-binding protein-related protein 2) in human fibroblasts: a potential mechanism for expansion of extracellular matrix in diabetes mellitus. Endocrinology 142:1760-1769

USRDS (2004) United States Renal Data System, USRDS 2004 Annual Data Report. National Institute of Diabetes and Digestive and Kidney Diseases, Bethesda, MA, USA, http:// www.usrds.org

Wahab NA, Yevdokimova N, Weston BS, Roberts T, Li XJ, Brinkman H, Mason RM (2001) Role of connective tissue growth factor in the pathogenesis of diabetic nephropathy. Biochem J 359:77-87 